\title{
LAS MUJERES ESPAÑOLAS Y LA CONSERVACIÓN DEL STATUS: EL RECURSO DE LAS INSTITUCIONES CRISTIANAS
}

Elizabeth Puertas Porras

Héctor Maldonado

\section{Introducción}

-1 1 presente estudio constituye una primera aproximación a la realidad que Wdebieron enfrentar las mujeres españolas establecidas en el territorio peruano durante las últimas décadas del siglo XVI y el transcurso del siglo XVII. Su caso es significativo porque ellas cumplieron la tarea de conservar y transmitir las costumbres y valores ptopios de lo occidental hispano que se buscaban generalizar en la sociedad colonial en formación.

Desde esta perspectiva, es innegable la fuerte presión que debieron experimentar estas mujeres en los primeros siglos de formación de la sociedad colonial. En efecto, las disposiciones de la Iglesia Católica, plenamente vigentes dentro de un orden social impregnado por la presencia de la fe religiosa, tendrán un peso crucial en la función asignada a la mujer. En este sentido, palabras como las que citamos a continuación serán tomadas en toda su magnitud por los encargados de difundirlas y hacerlas cumplir: 
[Sobre los oficios de la mujer] Sea su principal cuidado educar los hijos en el culto de la religión y cuidar con diligencia las cosas de la casa. Estense con mucho gusto recogidas en casa sin salir de ella si no las obliga la necesidad y nunca se atrevan a salir sin licencia de su marido. A más de esto tengan siempre presente que después de Dios a nadie deben amar ni estimar más que a su marido pues en esto señaladamente está afianzada la unión matrimonial y asimismo condescender con él y obedecerle con muchísimo gusto en todas las cosas no son contratias a la piedad cristiana.'

Normas derivadas de ideales como los aquí expresados se desarrollaton e hicieron presentes en las vidas de todas las mujeres que habitaban los territorios donde la reforma católica se lievó cabo. ¿Qué cabría esperar, entonces, como destino para aquellas que debian velar porque estos ideales cobraran vida en los individuos concretos? Haríamos mal en considerar que las mujeres venidas de España gozaban de algún tipo de protección o beneficio en la medida que se les reconocía su importancia como transmisoras de los elementos esenciales de la occidentalidad hispana. Las mujeres españolas adquirian dicho estatus solo si se hallaban perfectamente ubicadas en el interior de la sociedad y cumpliendo alguno de los roles destinados a ellas, es decir, madre, esposa o hija de ciudadanos reconocidos por su honra y buen nombre. No debe caber duda, entonces, de que ante las sombrías perspectivas que representaba el hallarse marginado de este oxden social se debiera emplear recursos diversos para mantenerse en él.

Nuestra interrogante principal se refiere a los mecanismos de respuesta que idearon las mujeres españolas en los distintos niveles sociales en los que se encontraron para enfrentar situaciones tales como la viudez (principalmente eatre las de elevado estatus), la ausencia de bienes para la dote matrimonial 
o la simple carencia de recursos económicos (problemas propios de aquellas de menor rango social) $y$, al mismo tiempo, lograr mantenerse dentro del sistema.

Resulta aparentemente contradictorio observar el modo en que de la propia Iglesia derivaban tanto normas que controlaban la conducta de las mujeres, al punto de convertirlas en marginales si no actuaban de acuerdo con los parámetros impuestos para ellas, como posibilidades de conservar posiciones de decisión que teóricamente les estaban vedadas y de mantenerse dentro del sistema como señoras respetables aun cuando su práctica cotidiana no se ajustara a los ideales difundidos desde la normativa religiosa. A fin de sustentar esta afirmación, hemos seleccionado algunos casos de mujeres españolas o criollas de niveles sociales altos y medios bajos que tienen como caracteristica común haber logrado mantener el estatus que de por sỉ les correspondía, al tratarse de mujeres hispanas, mediante el uso de distintos recursos derivados, en su mayor parte, de los medios proporcionados por la institucionalidad religiosa.

\section{De encomenderas a abadesas: las mujeres hispanas} y los medios para conservar los puestos de dominio adquiridos

La existencia de grandes propiedades territoriales en manos de mujeres fue una realidad que se presentó con mayor frecuencia de la que se hubiera deseado. Este fenómeno partió de la propia naturaleza de las leyes que con respecto a las propiedades existian. Sellegó a aceptar que tanto hijas como esposas de encomenderos difuntos se mantuvieran en la posesión de estas propiedades, pero, para evitar que estas permanecieran en manos de mujeres, a quienes quedaban viudas se les presionaba para que contrajeran nuevo 
matrimonio, Dada la situación de conflicto que se vivia en los primeros años de la conquista, momento al que corresponde la entrega de este tipo de posesiones, muchas mujeres quedaban en situación de viudez en más de una oportunidad. Este hecho redundó en la formación de grandes emporios productivos constituidos por las encomiendas y bajo la autoridad de mujeres, que gracias a ello se hallaron en condición de ejercer formas de poder e influencia derivadas de la riqueza con que contaban.

El que este tipo de autoridad fuera reconocido a las mujeres trae preguntas relacionadas con las razones existentes para ello. Estas parecen haber tenido que ver con las actitudes que estas mujeres tomaron en relación con elorden patriarcal dentro del cual vivian. Lagran mayoria de las encomenderas estaba constituida por españolas o criollas, mujeres destinadas a conservar y reproducir los ideales de la vida señorial. $\mathrm{Si}$, de acuerdo con ellos, el lugar de la mujer estaba en el hogar a cargo de todo lo relacionado con las labores domésticas, ${ }^{2}$ es muy posible que las funciones cumplidas allende las barreras de la casa hayan sido vistas como una ampliación de las primeras en la medida que se trataba de llevar a una escala mayor los deberes que ya se ejecutaban al interior del dominio doméstico. Así, esta práctica no era percibida como una contradicción. Además, las funciones propias del papel de madre correspondían a las funciones de protección y enserianza de la religión cristiana que se esperaban de un encomendero para con sus indios.

Entre estas mujeres, que representan a cabalidad las características que los ideales señoriales atribuían a las mujeres aristócratas, el ejercicio de la caridad cristiana destaca como el modo más usado para marcar la diferencia de estatus social. Este hecho se manifiesta a través de donaciones a entidades caritativas o en su participación activa en la fundación de conventos y monasterios. En correspondencia con este hecho, es posible establecer una relación 
directa entre el papel jerárquico asumido por estas mujeres a lo largo de sus vidas y las funciones que algunas de ellas desempeñaron al final de estas.

Siguiendo las normas consideradas como las más adecuadas para mujeres honorables en estado de viudez,' las mujeres en dicha condición proceden a la distribución de sus bienes destinando gran parte de ellos a casas de recogimiento o a monasterios en los que ingresan en calidad de abadesas o prioras. Siguieron este camino señoras como doña Lucrecia de Sánsoles, fundadora del monasterio de Nuestra Señora de la Trinidad (1580), que invirtió la suma de cien mil pesos; y su hija doña Mencía de Vargas, quien aportó a la fundación la renta de su encomienda (Pucarani), valorizada en dos mil cuatrocientos setenta y ocho pesos anuales. Ambas ingresaron a dicho conventa en calidad de abadesa y primera priora, respectivamente. Asimismo, doña Lucía Guerra de la Daga, dama vinculada a Santa Rosa de Lima, tuvo un destino similar entregando todos sus bienes a la fundación del monasterio de Santa Catalina (1625), en el cual ejerció como abadesa. Por otra parte, doña Ana Rodríguez de Solórzano donó a la Hermandad de la Caridad unas fincas para el establecimiento de un hospital para mujeres y para el colegio Nuestra Señora del Socorro de niñas huérfanas. Ella ejerció, posteriormente, como priora de esta hermandad. ${ }^{b}$

Grandes e importante propiedades pasaron a la Iglesia de manos de damas, especialmente si eran viudas, a causa de la amplitud de facultades que tenían para disponer de sus bienes. Así, entre los mayores benefactores de instituciones religiosas se encuentran mujeres entre las que es posible mencionar a doña Usenda Loayza Valdez y Bazán, miembro de una importante familia cusqueña, quien dona en su testamento todas sus propiedades en el valle de Cupina al convento de La Merced del Cusca? Otto es el caso de doña Ana de Medina y sus dos hijas, doña Tomasa y doña 
Bernarda, quienes fundaron el monasterio de Nuestra Señora de las Mercedes en Lima (1718), contando para ello con el monto total de sus bienes que ascendian a ochenta mil pesos en casas.' Asimismo, puede referirse el caso de doña Catalina María Donia, que al quedar viuda y $\sin$ hijos entregó todos sus bienes por valor de noventa y seis mil pesos a las fundaciones que había hecho: un recogimiento o colegio de niñas (1626) y el monasterio de El Carmen (1643).

Los ideales señoriales imponían a quienes se consideraban miembros de este grupo una serie de deberes destinados a conservar su posición privilegiada. Características tales como el buen nombre, el honor y la antigüedad en la residencia, entre otros, eran signos propios de los socialmente superiores y debían hacerse evidentes. Las mujeres parecen haber preferido el ejercicio de la caridad cristiana como modo para destacarse del resto y como el mejot medio de conservar posiciones de privilegio actuando dentro de las reglas que el orden imperante les imponía.

\section{El matrimonio y las cofradías: la conservación}

\section{de estatus entre españolas de sectores medios y bajos}

Para este propósito, hemos seleccionado seis casos relativos a mujeres hispanas. Las tres primeras son representantes, cada de una de ellas, de lo que podemos considerar el promedio de vida propio de los sectores intermedios que lograron desarrollarse con éxito. Dentro de este grupo, destaca el amplio sector conformado por los inmigrantes españoles afincados a fines del siglo XVI en el virreinato peruano. Las tres últimas representan casos de mujeres que si bien no llegaron a ser consideradas marginales, sí debieron enfrentar serias dificultades para mantenerse como dignas y respetables, 
A continuación, señalaremos cuáles eran las präcticas cotidianas de estas mujeres para enfrentar los desafios que representaba el mantener, o cuanto menos aparentar, un estatus social acorde a su naturaleza de hispanas dentro de una sociedad que empezaba a constituirse siguiendo el modelo de la España de fines del siglo XVI, pero que, sin embargo, otorgaba una serie de espacios nuevos y distintos que, de un modo u otro, les permitieron emplear recursos que formal y tradicionalmente les habian estado vedados.

El primer caso al que hacemos referencia es el de Ana Muñoz," española nacida en Sevilla, quien cuenta como única posesión con la dote que llevó a su matrimonio. A pesar de lo limitado de la cantidad (27 mil maravedíes), esta le permitió contraer matrimonio y establecerse. Ella representa lo que podemos considerar el prototipo de la mujer casada adecuadamente en su época y que tuvo la posibilidad de llevar una vida tranquila gracias a si matrimonio y de desenvolverse sin mayores dificultades dentro de las limitaciones que se imponía a las mujeres en su época. Constatamos, así, que entre los beneficiarios de sus bienes se encuentran su esposo, Garci Hernández de Medinilla, la hija de este y el monasterio de monjas de Santa Ana, en Sevilla, adernás de instituciones caritativas. Se trató de una ferviente devota, hecho que queda demostrado por su pertenencia a las cofradias del Santísimo Sacramento y del Rosario, También fue hermana de la Orden de San Francisco y dispuso que a su muerte se la sepultara vestida con el hábito de Nuestra Señora de la Merced en el templo de este nombre, además de establecer al detalle la forma de sus funetales. Ella muestra tener plena confianza en su esposo, al cual nombra albacea de sus bienes disponiendo explícitamente que se evite tomarle cualquier tipo de cuentas con respecto a la distribución que haga de los mismos, al tiempo que le otorga una 
considerable participación en estos. Medidas como las mencionadas dan cuenta de que nos hallamos frente a una mujer que encajaba perfectamente en el ideal correspondiente a las damas de su época, dado que mantenía el recogimiento en su hogar y se regía por las normas impuestas respecto al modo de ejercer la caridad y expresar la devoción religiosa.

El segundo caso que presentamos es el de Catalina Montes de Oca," hija de españoles nacida en Puerto Rico y casada con Cristóbal de Velasco. A ella se le atribuye la propiedad de una hacienda en la ciudad de Piura, la mitad de las casas principales «que son de Gonzalo Alonso de Camachom, la mitad de una estancia en el valle de Malinzas y el ganado contenido en ella; además de setecientas cabezas de ovejas, ochenta cabras y quince cabezas de yeguas. El caso de esta mujer destaca por el número de sus posesiones y, especialmente, porque afirma que todas fueron obtenidas dumante su matrimonio, inclusive se llega a manifestar que contrajo nupcias sin entregar dote, a pesar de lo que consta en la carta que su marido le entregó como constancia de haberla recibido. Aquí nos hallamos frente a una situación bastante más común de lo que podría parecer, pero, sobre todo, en los casos de mujeres indias y no así en el de españolas. Catalina Montes de Oca nombra como única heredera a su hija doña Agustina, a quien afirma le pertenecen tanto sus bienes como los de su padre. En relación con las disposiciones funerarias a que se ha hecho mención, estas se limitan a designar como lugar de entierro el monasterio de San Agustin, sin hacer referencia detallada a ouras disposiciones. Podemos observar que este seria un caso típico en el cual el hallarse fuera de la rígida normatividad matrimonial vigente en España permitió a esta mujer contraer nupcias aun a pesar de no contar con una cantidad destinada a servirle como dote. Este matrimonio le otorgó un estatus digno y le permitió detentar una serie de posesiones. 
Otro caso que es posible ubicar dentro de este grupo, a pesar de la peculiaridad que exhibe, es el de Juana de Robles. ${ }^{12}$ Fue originaria de la villa de Caravaca en España y viuda del lienciado Pedro Díaz de Turín, quien en vida se desempeñó como relator del crimen ante la Real Audiencia. Quedó con la responsabilidad de hacerse cargo de los cinco hijos que le sobrevivieron y encontró los medios para ello en el desarrollo de una actividad, cuando menos, poco usual en tétminos formales. Ella tuvo a su cargo una empresa de comercio de vinos entre Lima e lca en la que se desempeña en compañia de uno de sus hijos. $\mathrm{Al}$ respecto, hace referencia en su testamento a cantidades ascendientes a trescientos veinte pesos por viaje, destinadas a la compra de vinos, y otro tanto para la adquisición de aditamentos destinados al transporte de los mismos. Resalta el hecho de que al momento de hacer mención a las deudas que tienen con ella señala, en primer lugar, a su hijo Diego de Robles, quien tiene pendiente traer «doscientas cinco botijas" con las que fue enviado a Ica por vino.

La participación directa de una mujer en actividades comerciales era algo considerado en extremo impropio para la época en la medida que este hecho implicaba, entre otras cosas, la necesidad de entablar relaciones con individuos que en muchos casos se hallaban más allá del entorno familiar. En este caso se halló Juana de Robles, que hace mención a los participantes encargados de los detalles del transporte de la mercancia con que comenciaba. Juana de Robles destaca también por la posesión de una serie de bienes inmuebles en la ciudad de Lima, entre los que se cuentan tres pares de casas, kunas junto al Santo Oficio y otras a espaldas de San Francíscow, además de las ubicadas en el barrio de Santa Ana.

En definitiva, el nivel económico ostentado por esta señora era superior al promedio, muy posiblemente a causa de su participación en las 
actividades comerciales mencionadas. ${ }^{2}$ Este hecho le permitió contar con los medios necesarios para distribuir entre sus herederos los bienes que les correspondían. Así, estando aún con vida, repartió a sus hijos la herencia que les correspondia por parte de su padre: un esclavo y cuatrocientos pesos a su hija Luisa, trescientos pesos en ropa a Isabel, $y$ un esclavo a Diego.

Además de estos casos, existieron otros en los que las mujeres hispanas no se diferenciaron de la mayoritaria población mestiza e indígena, pues apenas contaban con lo imprescindible para sobrevivir y cumplir de modo bastante limitado con los auxilios espirituales para sus aimas al momento de la muerte. Destaca aquí el hecho de que las disposiciones funerarias, entre las cuales incluimos las obras caritativas, adquieren una importancia central frente a otros posibles destinos de los exiguos bienes con que contaban.

Encontramos, en este grupo, casos como el de Teresa Valles, "quien, natural de la villa de Palos en Esspaña, viuda del tarifero Francisco Herrera y madre de un hijo, manifestó tener entre sus bienes únicamente a una esclava y a tres de los hijos de esta, además de efectos personales y los muebles de su casa. Esta mujer designó como único heredero a su hijo legítimo, también de oficio tarifero, y encargó a sus albaceas el cobro de trescientos setenta y un pesos que le debian distintas personas. Asimismo, indicó se le solicitara a Antón Rodríguez, personaje al que debía cincuenta pesos, le hiciera merced de los mismos en atención a su mucha necesidad. Menciona, además, pertenecer a las cofradías del Santisimo Sacramento, de Nuestra Señora del Rosario, de la Capilla de la Cárcel y de la Capilla de Ánimas del Purgatorio. Del mismo modo, señala que al momento de su muerte se le entierre en la iglesia de Santo Domingo. Como podemos apreciar, a pesar de tratarse de una mujer que logró contraer matrimonio y establecerse como esposa de un artesano, su estado de viudez la colocó en una dificil situación económica. 
Los casos siguientes corresponden a dos mujeres que también quedaron viudas y carentes de bienes que les permitieran llevar una vida holgada. Tenemos, asi, a Mariana de Cevallos, ${ }^{15}$ natural de San Sebastián y viuda de Francisco del Lunar. Ella no tuvo hijos y consigna como únicos bienes doscientos pesos en plata corriente y doscientos en joyas de oro, además de ropa y objetos personales que reparte entre un individuo de nombre Juan de Zevallos y su única heredera, Juana del Lunar, su cuñada, con la condición para esta última de permanecer a su lado. Como única petición funeraria, solicita ser sepultada en la capilla de San Juan de Letrán vistiendo el hábito de Santo Domingo.

El siguiente y último caso es el de Isabel Jerónima, ${ }^{\text {th }}$ natural de Sevilla y viuda de jorge Cabra. Tampoco tuvo hijo y menciona como únicos bienes ropa y objetos personales, que solicita a su albacea se vendan y sirvan para el auxilio de su alma y para su entierro en el templo de La Merced.

Como podemos advertir se ha tratado de presentar una muestra que ha buscado ser representativa de las distintas situaciones que tuvieron que enfrentar mujeres que llevaban sobre sí el peso de tener que reproducir el sistema dentro del que habían nacido. Nos encontramos con casos que van desde posiciones perfectamente adecuadas y previstas como lo más deseable para una mujer española hasta situaciones en las que se debió dejar de lado los moldes impuestos con el fin de mantener el nivel socioeconómico alcanzado.

\section{Conclusiones}

Esta aproximación al tema nos permite concluir que la proximidad a instituciones y formas de ordenamiento derivadas del cristianismo católico fue empleada 
por mujeres provenientes de la radición occidental como el medio mâs idóneo para conservar las posiciones que la complejidad del medio indiano les habia permitido adquirir.

Aquellas mujeres que se ubicaron en elevados niveles de la sociedad $y$ lograron ocupar puestos de poder e influencia intentan conservarlos ingresando en puestos de dirección a instituciones religiosas que reproducen en pequeño el orden social imperante, como es el caso de los monasterios.

Entre las mujeres de niveles medios e inferiores se observa que el matrimonio no siempre garantizaba el alcanzar y mantener el tan anhelado estatus social y económico al que aspiraban, dado que situaciones como la muerte prematura del cónyuge podian precipitar cambios radicales en este sentido,

Las posibilidades de salir airosas con una respuesta desusada frente a condiciones adversas parecen haber estado limitadas a casos de mujeres que contaran con cierta holgura económica, además de relaciones que les permitieran desenvolverse con cierta libertad. De este modo, se limitó el siempre existente peligro de ser censuradas por sus actividades y arrastrar con ello el buen nombre de sus familias.

Otra conclusión giraria en torno al caso de las mujeres más pobres y la fuerte vinculación que establecen con instituciones religiosas, llámense cofradias, hermandades o entidades caritativas. En atención al elevado número de menciones que en este sentido sc hacen, resulta evidente que ellas destinaban gran parte de su tiempo a estas prácticas, las que, al parecer, constituían un medio para mantenerse ligadas al tejido social que amenazaba con marginarlas. 


\section{Notas}

'Concilio de Trento, E. 376.

${ }^{2}$ Cfr. Atieza, lgnacio wMujer e ideologia: una visión "EMIC" del papel de la mujer aristócrata en el siglo XVIIn. Revista Internacional de Sociologia, vol. 47, n. ${ }^{*} 3,1989$, p. 328.

'Cft ibidem, p. 328 .

"Cfr. Guerra Martinière, Margarita. La mujer en la conquista y la evangelización en el Penti. Limia 1550-1650. Lima: Pontificia Universidad Católica del Perú, 1997, pp. 308-309.

Cfr. García y Garcia, Elvira. La mujer peruana a través de los sighos. Lima: Imprenta Americana, 1924, pp. 125-126.

"Cfr. ibidem, p. 236.

'Cfr. Mendiburu, Manuel. Diccionario bistónico-biografico del Penḱ. Tomo 7. Lima: Imprenta Enrique Palacios, 1932, p. 62.

"Cfr, ibidem, p. 160.

"Cfr. García y García, E., op. cit, p. 139.

${ }^{10} \mathrm{C}$ fr. Archivo Gencral de la Nación. Protocolos notariales: Juan Gutiérrez, 71, 1573, fols. $828-830 \mathrm{v}$.

"Cff. Archiva General de la Nación, Protocolos notariales: Juan Gutiérrez 73, 1578, fols. 263-265 v.

${ }^{42}$ Cfr. Archivo General de la Nación. Protocolos notariales: Marcos Franco de Esquivel, 34. 1578, fols. $549-551$.

is $\mathrm{Si}$ consideramos que el sueldo promedio anual de un relator de la Real Audiencia era de 1082 pesos anuales, resulta casi obligatorio considerat que el resto de los ingresos aqui considetados provenian de otras fuentes.

"Cfr. Archivo General de la Nación. Protocolos notariales: Marcos Franco de Esquipel, 33, 1570 , fols. $67-69$.

${ }^{15}$ Cfr. Archivo General de la Nación. Protocolos notariales: Mareos Franco de Esquivel, 33, 1575 , fols. 483-485 v

"Cfr. Archivo General de la Nación. Protocolos notariales: Marcos Franco de Esquivel, 35, 1580 , fols. $100-102$. 